\title{
Sexual Dimorphism in A Cross River Ecotype Local Chicken - Rose Comb (Gallus Gallus Domesticus)
}

\author{
Hannah Edim Etta ${ }^{1 *}$ and Kogbara, Henry Barizigakol ${ }^{2}$ \\ ${ }^{1}$ Biological Sciences Department, Cross River University of Technolog \\ Calabar, Cross River State, Nigeria \\ ${ }^{2}$ Department of Genetics and Biotechnology, University of Calabar \\ Calabar, Cross River State, Nigeria \\ "Corresponding author's email: sarahrhoda [AT] yahoo.co.uk
}

\begin{abstract}
Sexual dimorphism in the local chicken (Gallus gallus domesticus)-Rose Comb- in Cross River was investigated. Sixty (60) male and female Gallus gallus domesticus chickens were evaluated for the effect of sex on body weight $(B W)$, body length $(B L)$, body girth $(B G)$, thigh length $(T L)$, shank length $(S L)$ and keel length $(K L)$ which were measured fortnightly for twelve (12) weeks. Sexual Size Dimorphism Index (SSDI) and Sexual Dimorphism Index (SDI) were used to confirm relative contribution of each trait to total dimorphism. The values obtained for SSDI and SDI respectively were 1.61 and $61 \%$ for $B W ; 1.26$ and $26.52 \%$ for $T L ; 1.23$ and $23.81 \%$ for $S L ; 1.22$ and $21.50 \%$ for $B L$; 1.18 and $18.20 \%$ for $B G ; 1.17$ and $17.94 \%$ for $K L$. To identify the best trait for predicting sex, stepwise discriminate analysis was employed and the Wilk's Lamda values obtained were BW(0.471); TL(0.452); SL(0.401); BL(0.283); $B G(0.272)$ and $K L(0.271)$. Results showed that there were significant $(p<0.05)$ differences in all measured parameters at week 6 with mean BW, BL, BG, SL, KL and TL of 300.01 and 253.24; 22 and 18.62; 5.20 and 3.98; 4.60 and 3.50; 5.50 and 3.90; 13.10 and 11.20 for both male and female birds respectively. These results indicate that sexual dimorphism is exhibited in all morphometric traits in favor of the male with $\mathrm{BW}$ as the highest dimorphic trait.
\end{abstract}

Keywords--- Sexual dimorphism; Local chicken; Rose comb; Gallus gallus domesticus; Cross River; SDI; SSDI

\section{INTRODUCTION}

Sexual dimorphism describes the systematic differences in form between individuals of different sexes in the same species. These differences can be in presence of parts of the body used in struggles for dominance, such as horns, antlers, tusks, size of the eyes (eg. in bees), colour (most birds), possession of stings (various kinds of bees), body size and different thresholds for certain behaviors. In some species including mammals, the male is larger than the female, yet in others like the spiders, the females are larger (Diego, Fernando and Nicola, 2004). In chickens, sexual dimorphism has been measured in both quantitative and qualitative traits as well as Carcass composition (Coyne, Kay and Pruett - Jones, 2008). Plumage dimorphism in the form of ornamentation or coloration also varies, though males are typically the more ornamented or brightly coloured sex (Diego, Fernando and Nicola, 2004). The phenomenon of sexual dimorphism is a direct product of evaluation by natural selection, in that the struggle for reproductive successes drives male and female organisms down different evolutionary paths. It is also a product of both genetics and environmental factors (Stamps, 1993).

Due to the influx and wide acceptability of the exotic chicken breeds in our markets today, despite all efforts by governments to control the importation of frozen and packaged chicken parts, there is a confirmed fear of our local breeds( including the Rose comb) going into extinction(ILRI, 2006). To avoid this, there is the need to explore the best breeding systems for the indigenous chicken breeds and practical knowledge of the sexual dimorphism in these breed is an important tool in this direction.

The Cross River ecotype local chicken (Rose comb) is called "Ata Unen" or "Unen Efik" by the Efiks, the ejagham call it...., the bekwarra call it ..... It is scientifically known as Gallus gallus domesticus and is native to Southern Asia, particularly the jungles of India though it has become indigenized here in Nigeria; Gallus gallus spread all over the world when people domesticated the chicken(Philips 1999, Stevens 1991 Peterson and Brisben 1999). Gallus gallus' plumage is gold, red, brown, dark maroon, orange, with a bit of metallic green and gray (Plate 1). 


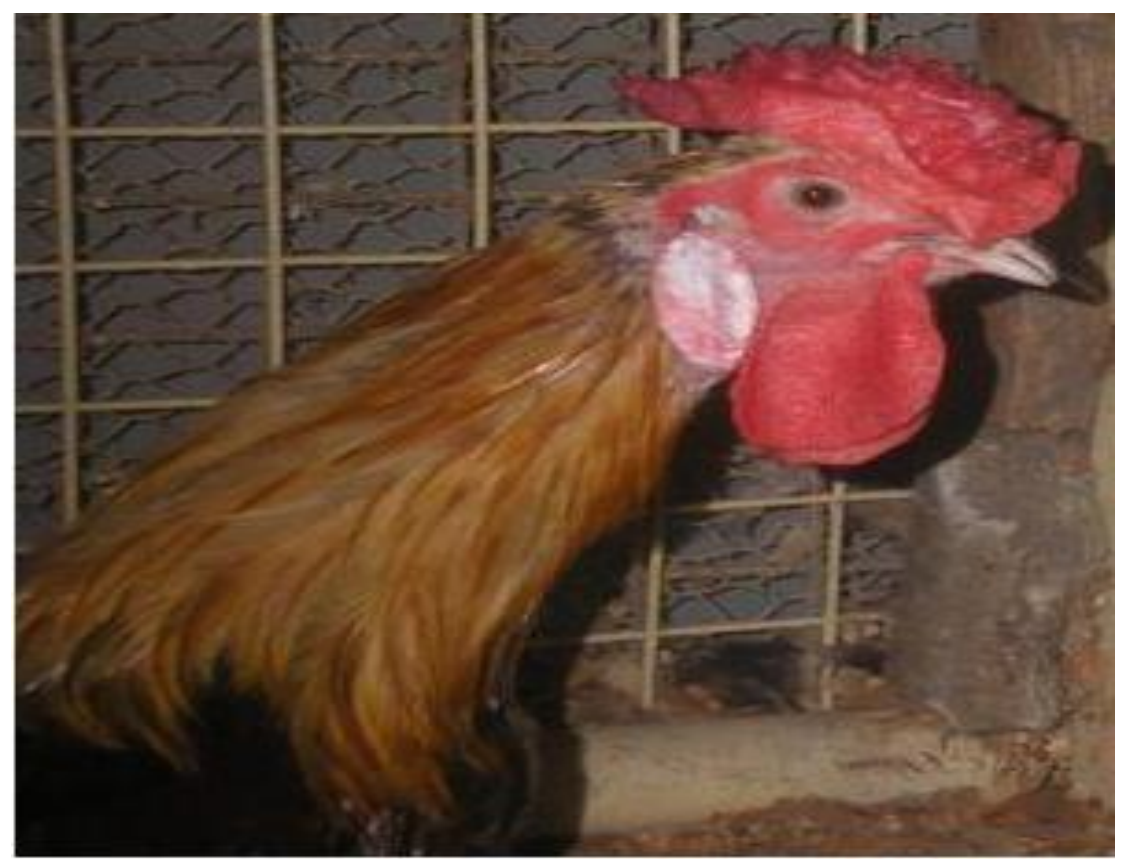

Plate 1: Gallus gallus domesticus

\section{MATERIALS AND METHODS}

A total of 60 day - old rose comb chicks ( 30 males and 30 females) were purchased for this study. The birds were randomly allocated to deep litter brooder pens and given a floor space of about $1.45 \mathrm{~m}$ per bird as suggested by Adejoro, (2002). Each chick was wing - tagged and examined physically to ensure fitness and general body soundness.

They were raised for a period of 12 weeks, placed on the same diets as recommended by NRC (1994) for chick and growing pullets. All the necessary vaccinations and medication were administered to the birds accordingly. Measurement of body weight and body parts was carried out fortnightly for 12 weeks. The body weight was measured in grams using Scott II electronic sensation scale and top loading mettle Balance. Other linear body parts were measured with tape rule and vernier caliper. The following linear body measurements were taken:

Body length: The linear distance between the nasal opening and the top of pygostlye when the neck in is carefully stretched. Body girth: The region around breast of the bird.

Shank Length: The distance from the foot pad to the hock joint.

Shank Diameter: it was taken as the middle of the left shank of each bird.

Thigh length: Measured from the tip of the tarsus to the ball joint.

Keel length: Measured from the cranial to the caudal terminal s of the keel bone.

Wing length: Measured by stretching the wing and the measurement taken from the humorous to coracoids junctions to the tip of the digit.

The drumstick length: Measured from the tip of the hock joint to the ball joint of femur.

Data collected from the measurements of morphological traits were analyzed using the SPSS ver 17.0 evaluation version software. Students T-test was used to test for significant differences in the morphometric traits of male and female Gallus gallus domesticus. Sexual dimorphism index (SDI) and sexual size dimorphism index (SSDI) were calculated using the formulae below respectively:

$$
\begin{aligned}
& \mathrm{SSDI}=\left(\bar{x}_{\mathrm{m}}-\bar{x}_{\mathrm{f}}\right) \times 100 / \bar{x}_{\mathrm{f}} \\
& \mathrm{SDI}=\bar{x}_{\mathrm{M}} / \bar{x}_{\mathrm{f}}
\end{aligned}
$$

(Weidinger and van Frameker, 2003).

Where $\bar{x}_{\mathrm{m}}$ and $\bar{x}_{\mathrm{f}}$ are the mean values of males and females respectively. The SDI and SSDI values were used to estimate the relative contribution of each of the morphological trait to the overall sexual dimorphism.

Step-wise discriminate analysis procedure was employed to identify important predictors that could efficiently discriminate adult male and female Gallus gallus domesticus. Multivariate analysis of variance (MANOVA) was used to test for significant differences within the group means on a combination of dependent variables. Wilk's lambda was used to assess the relative discriminating ability of each of the morphological traits using the formula;

$$
\lambda=\frac{/ \mathrm{E} /}{/ \mathrm{H}+\mathrm{E} /}
$$

Where $\mathrm{E}$ is error sum of squares; $\mathrm{H}$ is hypothesis sum of squares.

\section{RESULTS AND DISCUSSION}


The descriptive statistics of body measurements of adult male and female Gallus gallus domesticus at 12 weeks are shown on Table 1 and 2. The SDI and SSDI values presented in Table 3 show that sexual size dimorphism was exhibited in all morphological traits. The SDI and SSDI were significantly $(\mathrm{P}<0.05)$ higher in body weight followed by thigh length and shank length, indicating that body weight factor is the most sexual dimorphic traits, which favored the male Gallus gallus.

Table 4 shows the result of step-wise discriminate analysis, which is in tandem with SDI and SSDI values, indicating that all the morphological traits are significant $(\mathrm{P}<0.005)$ in separating adult Gallus gallus domesticus into male and female. Body weight is the highest discriminating factor and keel length is the least as shown in fig.2.

From the results presented, the male Gallus gallus domesticus were significantly $(\mathrm{P}<0.05)$ larger in body weight, body length and body girth than the females from 6 weeks of age and above. From 0 to 4 weeks (28days), the body weight, body length and body girth differences were not significant $(\mathrm{P}>0.05)$. These results are slightly different from summations of several other researchers who reported that body weight differences between the sexes are observed right from the embryonic stage (Burke and Sharp, 1989; Mark, 1985). The diet or environment may be implicated in the observed similarities in body weight up till 28 days. The shank length and thigh length of male Gallus gallus domesticus were not significantly $(\mathrm{P}>0.05)$ different from that of the females at day old to 4weeks of age, but significantly $(\mathrm{P}<0.05)$ different in both sexes at latter age i.e. 6 weeks and above. The keel length of male Gallus gallus domesticus were not significantly $(\mathrm{P}>0.05)$ different compared to their females counterpart within 0 to 4 week old but also significant $(\mathrm{P}<0.05)$ from 6 weeks and above.

Table1: The effect of sex on body weight, body length and body girth of male and female local chickens in Cross River State

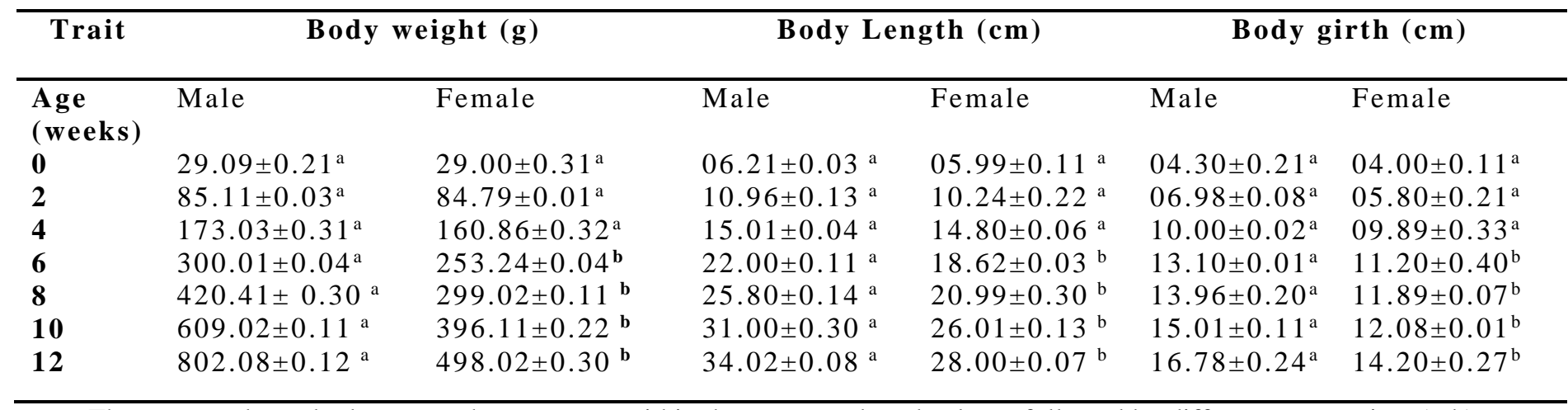

The mean and standard error on the same row within the same week and column followed by different superscripts (a-b) differ significantly $(\mathrm{p}<0.05)$.

The increase in body length and higher mean values for body girth in males are indicative of meatiness (Oguntunji and Ayorinde, 2014).

These results showed significant $(\mathrm{P}<0.05)$ differences in adult male and female Gallus gallus domesticus in body weight and other morphological traits precisely at 6 weeks of age. The present study thus proved that Gallus gallus domesticus can be separated into male and female using their morphological traits at the age of 6 weeks and above. The above results are slightly different compared to that of Manchal et al. (2008) and sola-Ojo et al., (2011) where significant differences in weight for both sexes were reported at 8 weeks of age in Fulani Ecotype chicken and local chickens in plateau State, Nigeria. However, it is similar to the reports by Oguntunji and Ayorinde (2014).

The rate of increase in both sexes occurs rapidly from day old to 4 weeks of age and slows down at later age, indicating that poultry maximize their weight gain at an early stage in life (Nwosu et al., 1985) and then grow at a slower rate as they approach puberty (Oluyemic and Oyenuga, 1974; Nwosu, 1979; Ayorinde, 1995). Descriptive statistics favoured the males to females for all morphometric traits with body weight as the most dimorphic trait (Fig. 2). This corroborates earlier studies on Muscovy ducks (Ogah et al., 2009 and Yakubu, 2011) where body weight was reported to be the most important discriminating variable. Owens and Short (1995), also proposed the hormonal basis of sexual dimorphism in birds. It could be that the hormonal milieu of both male and female birds did influence their degree of dimorphism.

The SDI and SSDI values indicate the contribution of each of the morphological traits to the total sexual dimorphism. SDI and SSDI is higher in body weight, 1.61 and 61\%, followed by thigh length, 1.26 and 26.52\%, Shank length, 1.23 and $23.81 \%$, body length, 1.2

Table 2: The effects of sex on thigh length, keel length and shank length of male and female local chickens in Cross River State 


\begin{tabular}{|c|c|c|c|c|c|c|}
\hline \multirow{2}{*}{$\begin{array}{l}\text { Trait } \\
\text { Age } \\
\text { (Weeks) }\end{array}$} & \multicolumn{2}{|c|}{ Thigh length $(\mathrm{cm})$} & \multicolumn{2}{|c|}{ Shank Length $(\mathrm{cm})$} & \multicolumn{2}{|c|}{ Keel length(cm) } \\
\hline & Male & Female & Male & Female & Male & Female \\
\hline 0 & $1.50 \pm 0.03^{\mathrm{a}}$ & $1.49 \pm 0.04^{\mathrm{a}}$ & $1.22 \pm 0.08^{\mathrm{a}}$ & $1.01 \pm 0.20^{\mathrm{a}}$ & $1.01 \pm 0.22^{\mathrm{a}}$ & $1.01 \pm 0.309$ \\
\hline 2 & $2.90 \pm 0.08^{\mathrm{a}}$ & $2.00 \pm 0.30^{\mathrm{a}}$ & $2.80 \pm 0.31^{\mathrm{a}}$ & $2.50 \pm 0.33^{\mathrm{a}}$ & $2.70 \pm 0.02^{\mathrm{a}}$ & $2.60 \pm 0.21^{\mathrm{a}}$ \\
\hline 4 & $4.01 \pm 0.11^{\mathrm{a}}$ & $3.78 \pm 0.20^{\mathrm{a}}$ & $4.01 \pm 0.12^{\mathrm{a}}$ & $3.98 \pm 0.41^{\mathrm{a}}$ & $4.01 \pm 0.01^{\mathrm{a}}$ & $3.06 \pm 0.02^{\mathrm{a}}$ \\
\hline 6 & $5.50 \pm 0.22^{\mathrm{a}}$ & $3.90 \pm 0.11^{\mathrm{b}}$ & $5.20 \pm 0.10^{\mathrm{a}}$ & $3.98 \pm 0.20^{\mathrm{b}}$ & $4.60 \pm 0.08^{\mathrm{a}}$ & $3.50 \pm 0.22^{\mathrm{b}}$ \\
\hline 8 & $7.00 \pm 0.30^{\mathrm{a}}$ & $4.98 \pm 0.32^{\mathrm{b}}$ & $5.98 \pm 0.30^{\mathrm{a}}$ & $4.02 \pm 0.34^{\mathrm{b}}$ & $6.00 \pm 0.21^{\mathrm{a}}$ & $4.20 \pm 0.30^{\mathrm{b}}$ \\
\hline 10 & $8.21 \pm 0.30^{\mathrm{a}}$ & $6.80 \pm 0.28^{\mathrm{b}}$ & $6.50 \pm 0.11^{\mathrm{a}}$ & $5.00 \pm 0.021^{\mathrm{b}}$ & $6.80 \pm 0.11^{\mathrm{a}}$ & $5.30 \pm 0.11^{\mathrm{b}}$ \\
\hline 12 & $8.92 \pm 0.04^{\mathrm{a}}$ & $7.05 \pm 0.20^{\mathrm{b}}$ & $7.80 \pm 0.13^{\mathrm{a}}$ & $6.30 \pm 0.11^{\mathrm{b}}$ & $8.02 \pm 0.12^{\mathrm{a}}$ & $6.00 \pm 0.08^{b}$ \\
\hline
\end{tabular}

The mean and standard error on the same row within the same week and column followed by different superscripts (a-b) differ significantly $(\mathrm{p}<0.05)$

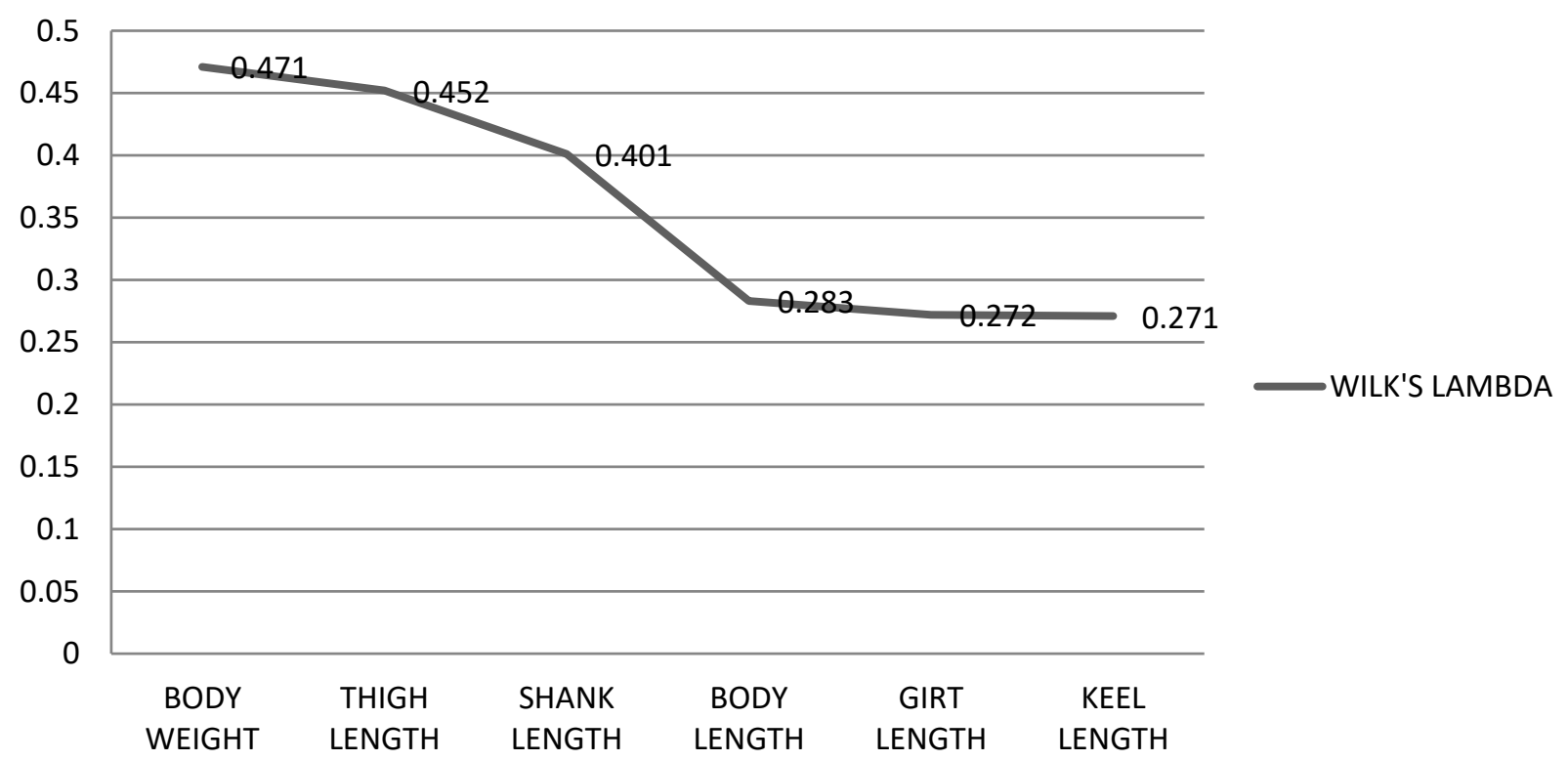

Fig.2: Line graph Showing body weight as the highest dimorphic trait at 0.471 and keel length as the least at 0.271 .

and $21.50 \%$, body girth, 1.8 and $18.20 \%$ and keel length with the least, 1.17 and $17.94 \%$. These results indicate that body weight made the highest contribution to the overall sexual dimorphism followed by the thigh length and shank length.

The SDI and SSDI values were male-biased in Gallus gallus domesticus. This agrees with the reports by Remes and Szekely, (2010) in their study on sexual size dimorphism (SSD) in chicken. They also proposed that SSD is a key evolutionary feature that is related to ecology, behavior and life histories of organisms. However, the higher SDI and SSDI values in favour of the male Gallus gallus domesticus in this report is in agreement with the result of Oguntunji and Ayorinde, (2014) on adapted Muscovy Ducks in Nigeria but the result of the step-wise discriminant analysis in this study is comparatively higher. This suggests that sexual size dimorphism is high among local chickens than the Muscovy Ducks (Remes and Szekely, 2010). 


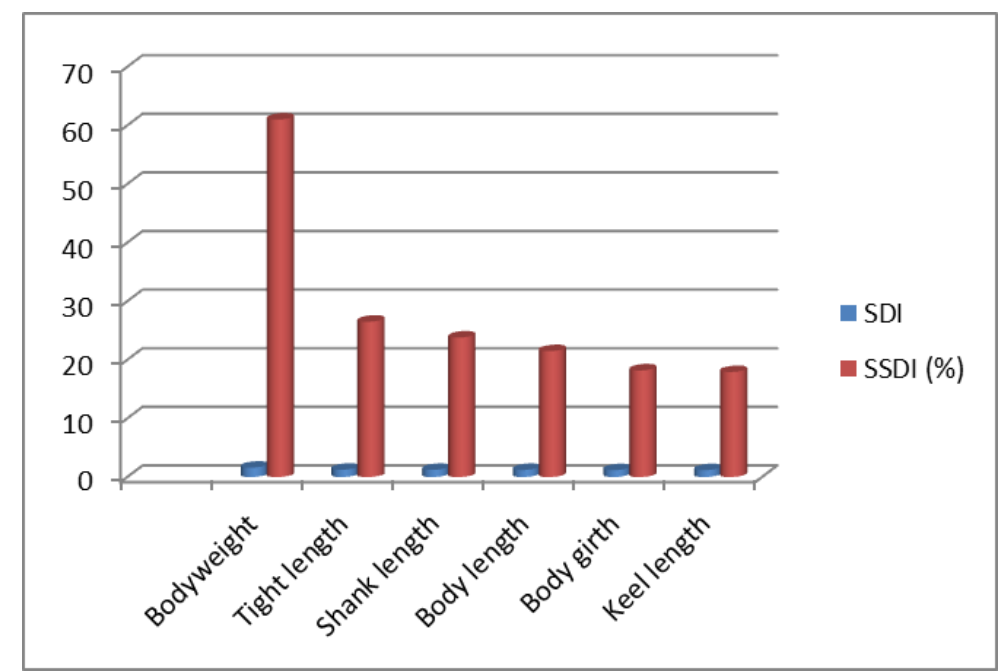

Fig. 3: SDI and SSDI values of morphological traits of adult local chickens in Cross River.

Table 4: Summary of step-wise discriminant analysis of adult male and female local chickens in Cross River State.

\begin{tabular}{lllll} 
Step & $\begin{array}{l}\text { Trait } \\
\text { entered }\end{array}$ & $\begin{array}{l}\text { Wilk's } \\
\text { lambda }\end{array}$ & F-value & P > F \\
\hline $\mathbf{1}$ & BW & 0.471 & $2.012 \mathrm{E} 3$ & 0.000 \\
$\mathbf{2}$ & TL & 0.452 & $1.673 \mathrm{E} 3$ & 0.000 \\
$\mathbf{3}$ & SL & 0.401 & 953.986 & 0.000 \\
$\mathbf{4}$ & BL & 0.283 & 821.031 & 0.000 \\
$\mathbf{5}$ & GL & 0.272 & 714.242 & 0.000 \\
$\mathbf{6}$ & KL & 0.271 & 621.124 & 0.000 \\
\hline
\end{tabular}

The results obtained from this study provide credible information on sexual dimorphism in Cross River State ecotype local chicken (Gallus gallus domesticus). Morphological traits (body weights, body length, body girth, keel length shank length, thigh length) can be used to separate Gallus gallus domesticus into male and female. This criterion is convenient at the age of 6 weeks and above, where the males appear larger than their female counterpart. The study also helps for the selection of Gallus gallus domesticus for improvement in meat production and address the problem of sex discrimination during selection for mating before sexual maturity.

The SSDI and SDI values in this report indicate that all the morphological traits exhibit sexual dimorphism, with male-skewed bias. The arrangement of the SSDI and SDI values in order of magnitude shows that body weight is the most dimorphic trait followed by body length, thigh length, shank length, body girth and keel length being the least dimorphic trait in adult

Gallus gallus domesticus. The result of the step-wise discriminant analysis is in tandem with the SDI and SSDI values suggesting that those morphological traits are important in sexing and assessing sexual size dimorphism (SSD) in Gallus gallus domesticus.

\section{SUMMARY AND CONCLUSION}

The results obtained from this study provide credible information on sexual dimorphism in Cross River State ecotype local chicken (Gallus gallus domesticus). Morphological traits (body weights, body length, body girth, keel length, shank length, thigh length) can be used to separate Gallus gallus domesticus into male and female. This criterion is convenient at the age of 6 weeks and above, where the males appear larger than their female counterpart. The study also helps for the selection of Gallus gallus domesticus for improvement in meat production and address the problem of sex discrimination during selection for mating before sexual maturity.

The SSDI and SDI values in this report indicate that all the morphological traits exhibit sexual dimorphism, with male-skewed bias. The arrangement of the SSDI and SDI values in order of magnitude shows that body weight is the most dimorphic trait followed by body length, thigh length, shank length, body girth and keel length being the least dimorphic trait in adult Gallus gallus domesticus. The result of the step-wise discriminant analysis is in tandem with the SDI and SSDI values suggesting that those morphological traits are important in sexing and assessing sexual size dimorphism (SSD) in Gallus gallus domesticus. 


\section{REFERENCES}

- Badyaev A.V., Hill G.E., Whittingham L.A. (2001). The evolution of sexual size dimorphism in House finch. In: Population divergence in ontogeny. Evolution,55,12: 2532-2549, doi:10.1111/j.0014-3820.2001.tb00767.

- Barua, A. and Y. Yoshimura, (1997). Rural Poultry keeping in Bangladesh. World's Poultry Science Journal, 53: 388-394.

- Besbes, O. Thieme, A. Rota, E. F. Gueye and R. G. Alders (2003). Technology and programme for substinable improvement of village poultry production. World poultry Sci. 25:24-26.

- Burke, W. H. and Snarp, P. J. (1989). Sex difference in body weight of chicken embrvos. Poultry Sci. 14:329340 .

- Coyne J.A., Kay E.H., Pruett-Jones S. (2007). The genetic basis of sexual dimorphism in birds. Evolution, 62, 1: 214-219.

- Farrell, D. J. Cumming, R. B. and Hardaker, J. B. (1973). The effect of dietary energy concentration on growth rate and conversion of British Poultry Sci. 14:329-340.

- Food and Agricultural Organization (FAO). (2009). The global plan of action for animal genetic resources and the Interlaken declaration on animal genetic resources. International Conference on animal genetic resources for food and Agriculture Interlaken, Switzerland.

- Fuzhu, I. and Q. Zhuye, 2008. Effect of sex on Carcarss characteristics of chicken. International Journal of Poultry Science, 7(4): 319- 322.

- Gehle, M. H. Powell, T. S. and Arendo, L. G. (1974). Effects of different feeding regimes on performance of broiler chickens reared sexes separate or combined. Poultry Sci. 53:1543-1548.

- International Livestock Research Institute (ILRI). (2006). Safe guarding livestock diversity: the time is now. ILRI Annual Report. Pp22-39.

- Jovbert, J.J., 1980. Selection Efficiency in the breeding of a Dominant White broiler fowl. Proceeding of South African Society of Animal Prodcution, 5: 160-162.

- Keshri, B. C., and Verma, S.S., Sinha, S.P., Sharma, R.P., Singh, P.B., Ray, A.K.D. and Shyamsunder, G. (1985). The relationship between live weight and eviscerated yield in pure bred broiler strains. Indian J. of Poultry Set. 20 (4):297 - 299. In: Poultry Abst. (1986) 12 (15) 126, 1089

- Kettlewell, p. (1986). Raise broilers in different age group. In: Poultry (Misset International Magazine on Poultry) $2(16): 12-13$

- Khan. A.G., Poulouse, M.V. and Chakraborti, S,(1975). Sexual dimorphism in the weight of chicks. British Poultry Sci. 1 6:637-639.

- Lang. B.J., Collins,W.M., Palmar, D.H and Skoglund, W.C. (1960). Relationship of sex separation to individual variation in body weight and to experimental error. Poultry Sci. 39:1578-1579.

- Le Behan - Dual, E., 2004. Genetic variability within and between breeds of poultry technological meat quality. World Poultry Science Journal, 60 : 331-340.

- Leenstra, F.R. (1986). Effect of age sex, genotype and environment on fat deposition in broiler chickens, A review. World Poultry Sci. 42:12-45.

- $\quad$ Limburg, P. (1975). Chickens, Chickens, Chickens . New York: Thomas Nelson Inc..

- Manchal, Y.P., S.T. Mbap and S.D. Abdul, 2008. An Assessments of observable and Measurable Traits as Possible Indices of Live weights in Local Chickens on the Jos Plateau of Nigeria. Nig. Poultry Science Journal, 5(1): 3-10. 
- Mandlekar, S, M, and Desmukh, S. N. (1983). Relationship between 8 week body weight and eviscerated weight in broiler chickens. Avian Res. 67(3),96-1 00.

- $\quad$ Mark, H. L. (1985). Sexual dimorphism in the early feed and water intake of broilers Poultry Sci. 64:425-428.

- Mark, H. L. (1987). Sexual dimorphism in broilers following periods of equal water and feed intake. Poultry Sci. 66:381-389

- Mark. H. L. (1986).The role of water intake of sexual dimorphism for early growth of broilers. Poultry Sci. 65:433435.

- McMeekan, C.P. (1940), Chemical composition of adipose tissue. In: Growth in animals (1980). pp.169. London, Butterworths.

- Meijerhof, R. (1988). Separate sex feeding at the Dutch regional experimental poultry farms. Proc, of the 4th International Poultry Breeders Conf. pp.40-46.

- Najib, H., Al-Aghbari, F. and Al-Malman, S. (1985). Broiler perforamnce as affected by age a slaughter under Saudi conditions. World Review of Ani. Prod, 21(4) 651-54.

- NRC, 1994. National Research Council, Nutrient Requirement Table of poultry, 9th edition Washington, D.C, National Academy Press.

- Olusegun, A. O. and K. L. Ayorinde, 2014. Sexual Size dimorphism and sex determination by morphometrie measurement in locally adapted Muscovy duck in Nigeria. Acta agricultural Scovenica, 104/1-2014.

- Oluyemi, J.A., 1974. Evaluation and Improvement of the Indigenous fowl of Nigeria. Ph. D Thesis, University of Ibadan, Nigeria, 25-30.

- $\quad$ Omeje, S.S.I and C.C. Nwosu, 1983. Egg production patterns in local chickens and their crosses in short term. Nig. Journal of Anim. Prod., 10: 91-96.

- Owens, I. P. F., Short, R.V. (1995). Hormonal basis of sexual dimorphism in birds: Implications for new theories of sexual selection. Trends in Ecology \& Evolution., 10 (REF), 44.

- Peterson, T., and L. Brisbin. (1999). Genetic endangerment of wild Red Jungle fowl Gallus gallus. Bird Conservation International, 9: 387-394.

- $\quad$ Philipps, C. (1999.) Feather Friends Classy chickens come home to roost. (On-line). Accessed July 28, 2000 (no longer available) at http://ptg.djnr.com/ccroot/asp/public/stroy.asp..

- Roche, J.F. and Quike, J,K, (1986). The effect of steroid hormones and xenobitotics on growth of farm animals. In: Control and manipulation of animal growth (1986) pp, 39-52. London, Butterworths.

- Sonaiya, E.B. William, A.R and Oni, S.A. (1986).A biologic and economic appraisal of broiler production up to 16 weeks, J. Anim. Prod. Res. 6(2) 115 - 125.

- $\quad$ SPSS. 2010. Statistical Package for Social Sciences. SPSS Inc., 444 Michigan Avenue, Chicago, IL60611.

- Stevens, L.(1991). Genetic and Evolution of the domestic fowl. New York: Cambridge University Press. Pp. 421 -433 .

- Summers, J. D. and Leeson, S. (1984), Influence of dietary protein and energy level on broiler performance and carcass composition. Nutr. Rep. Int. 29: 757 - 767.

- The management of global animal genetic resources: Proceedings of a FAO expert consultation, Rome, Italy, April 1992, Issue, 104. Food and Agriculture Organization of the United Nation, 1992.

- Yamani, K.A.O., Nowar, M.E., Marai, I.F.M., Irky, A.M, and Eid, A.M.S (1982). Studies of body measurements and dressing weights of broiler chicks. Egyptain J. of Anim. Prod. 22: 19-26. 